\title{
Influence and Function of the Customary Law of Ethnic Minorities on Environmental Protection
}

\author{
Hongqing Ma \\ Law School, China University of Political Science and Law, Beijing, China \\ Email address: \\ 1602010010@cupl.edu.cn,1957268851@qq.com \\ To cite this article: \\ Hongqing Ma. Influence and Function of the Customary Law of Ethnic Minorities on Environmental Protection. International Journal of \\ Environmental Protection and Policy. Vol. 9, No. 4, 2021, pp. 86-90. doi: 10.11648/j.ijepp.20210904.13
}

Received: July 29, 2021; Accepted: August 25, 2021; Published: August 31, 2021

\begin{abstract}
Customary law of ethnic minorities is recognized by ethnic groups with the same geographical and cultural environment, and formed through long-term practice in their social life. Most Chinese Customary Law of Ethnic Minorities had the tradition of natural worship activities, which originate from the worship of the natural, such as the heaven and the earth, landscape, animals, and plants, this has been provided the foundation for environmental protection. In order to further understand the function of corresponding law on environment, this study try to analyze the environmental protection significance by the customary law of ethnic minorities in consideration of the ancient environmental protection thought and the modern environmental protection case. The ideas from ancient Chinese philosopher has been introduced, and the regulation in ancient meteorites were analyzed. Then three kinds of minorities in China, such as Gelao nationality in Guizhou, Ganzi Tibetan, Jing minority, were described. For Gelao, their worship and respect for forest and mountain helped them to protect the natural resource. While for Ganzi Tibetan, they have holy mountains and rivers and formed many taboos and living customs to protect natural resources and animal resources due to their awe and respect for nature. These behavior surly helped to protect the environment. Jing minorities lived in the sea for long time, their belief for god of sea and mountain had helped them to protect the environment by a variety of methods such as village regulation, family words, as well as festival celebration. Then the roles of customary laws on environmental protection were discussed. The concept of "all things have spirit" inside customary law helped the local people for implementation of the laws, also benefited for the law legislation.
\end{abstract}

Keywords: Ethnic Minority, Nature Worship, Environmental Protection, Customary Law

\section{Introduction}

Customary laws are a social norm that people gradually and spontaneously form through long-term practice in their social life. Generally, customary laws are only recognized by ethnic groups with the same geographical and cultural environment. In ancient times, customary laws were an important legal source, but now they are gradually replaced by normative documents and case laws and are no longer the main source of rules. Article 10 of the Law of Regional National Autonomy stipulates that all nationalities have the freedom to maintain or reform their own customs. Therefore, the national custom is also the origin of our country's law. Environmental protection customary law is a part of the customary laws of ethnic minorities. Given that the ecological customary law of ethnic minorities is based on survival and practice in life, it has referential significance for the system belief path selection. Customary laws also have exemplary and empirical values due to their successful performance in ecological protection.

\section{Environmental Idea of Different Nationalities' Customary Laws}

China has 56 nationalities with corresponding customary laws about environmental protection. Different nationalities have different rules and laws, for example, "Lang rule," for Miao nationality, "Du Lao" system for Zhuang nationality, "payment agreement," for Dong nationality and Tibetan environmental customary law. The provisions of the national customary law could be fully utilized for the protection of natural resources and environment, which may be of great value and contribution for the protection of nature and 
environment. In Qiaoshiming's monograph, “The study of the construction of ecological environment legal system in minority areas," she comprehensively and systematically discussed the important position and the role played by the law of environmental protection of ethnic minorities in the construction of the ecological environment legal system of ethnic minorities [1].

Gao Qicai studied the customary law of environmental protection of ethnic minorities in "The theory of Chinese customary law" and "The Chinese customary law of ethnic minorities" [2, 3]. Liu Yigong and Shen Wei analyzed the prominent characteristics of the environmental protection customary law of ethnic minorities in the process of origin, content, expression, mode of action and, legal norms in the article "Brief discussion on the customary law of environmental protection of Chinese minorities" [4]. Other researchers have also used example of different minorities, such as $\mathrm{Li}, \mathrm{Yi}, \mathrm{Miao}$, and Dong minorities, to show the minority customary law in the protection of forest, grassland, and other natural resources.

In fact, there exists some environmental protection publications in ancient China for the Chinese ethnic minority on environmental protection. The Han literature has recorded the "strategy of black tartar," in which the Mongolian customary law stipulates that "those who have been in the prohibited period for grassland are not allowed to dig the land, and those who leave fire and grass will be punished for their families." The law indicates that no grassland shall be excavated during the growth of grass and wood, and protection from fire is extremely important. Those who violate the law shall be punished. The Mongolian people have long grasped the brief protection of grassland, attached importance to the growth of grass, and prohibited grassland fire. Genghis Khan also had the provisions of death penalty for those who urinate in water and in fire ash. This behavior is prohibited because urine in ash can cause fire, and grassland is prone to wildfires. Thus, the ancient ethnic minorities in China have the tradition of environmental protection.

\section{Case Study of Customary Laws of Different Ethnic Minorities on Environmental Protection}

The customary laws of different ethnic groups in modern times have different applications to environmental protection, which provide good protection for natural resources and animal life.

\subsection{Gelao Nationality in Guizhou}

In the Gelao area of Guizhou, there exists the "Fengshui forest," which is a bush full of trees. The villagers obey the rules to protect the forest mainly due to the fear of the punishment of the "old people" who will perform "Taoist court" and "killing three animals" for those who break the rules [5]. Once, villagers named Chen had entered the Fengshui forest and cut down two trees to build their houses.
The villagers named Chen were punished by the old people and made them perform a sacrifice for the gods, that is, to kill a chicken, a sheep, and a pig. The whole other people in the village were treated for three days to make a Taoist court to comfort the gods and avoid disasters. This event reflects that the Gelao ecological customary law is still one of the most important social norms. This law is closely related to their living habits. Gelao people in Guizhou have been living in the mountains for generations; they believe that trees provide them with shelter and contain spirit, and trees have thus become a sacred symbol in their hearts. This standard makes many trees and forests well protected. It promotes the balance of natural ecology in Gelao nationality living in Guizhou Province. In addition, the people are full of infinite mystical and fear toward the unpredictable nature. They revere the trees and rocks in nature and worship and pray for them, hoping that they can bless them [6].

On the third day of March of the lunar calendar, the Gelao people sacrifice and pray to the mountain god, Bodhisattva, to manage the mountain wasteland (wild animals and birds) and protect the safety of people and animals. Figure 1 shows how the Gelao people sacrifice to the mountain god. The first day of February is the traditional "King Sparrow Festival" of the Gelao people. They believe that once, an eagle had saved their ancestors when they were endangered, and the eagle has thus become their totem. In the process of this natural worship, ancient Gelao ancestors gradually produced many primitive worship and taboos. These regulations contain the ecological ethical value for respecting nature, loving human settlements, and harmonious coexistence between human and nature [7].

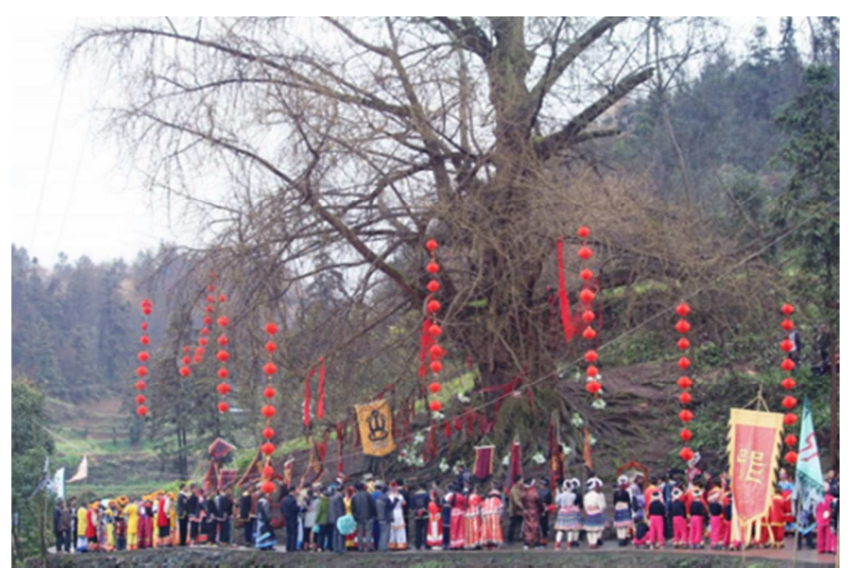

Figure 1. Gelao people praying to the mountain god.

\subsection{Ganzi Tibetan}

The Ganzi Prefecture has abundant water resources. Local people think that water is the source of life and is sacred. Therefore, certain taboos exist regarding the god of lake in Ganzi Tibetan area. To keep the water sacred and pure, dumping of garbage, drowning, and spitting in water sources, such as rivers and lakes, are prohibited, and fishing in the divine lake is not allowed. These simple rules protect the local water resources well [8].

Agriculture and animal husbandry are the main sources of 
living in Ganzi Tibetan area. Thus, the local people have a strong sense of land protection, mainly in the following three aspects. First, they implement a grassland rotation system. Grassland is divided into two seasons, namely, winter and summer, or four seasons - spring, summer, autumn, and winter. Grazing is performed according to different seasons. The utilization of grassland in consideration of resting and living can develop animal husbandry properly and maintain good grassland conditions. Second, digging around the land is strictly forbidden. The Ganzi Tibetan people believe that all things are spiritual, the land breeds all things in the world, and the land has real life. Once excavated, the surface will be injured and turn into a "dead land," which will destroy natural perfection, which is unfavorable to human beings. Third, punishment will be given to those who destroy grasslands or farmlands. Charge for money is the punishment mostly adopted, the intensity of which is quite strict.

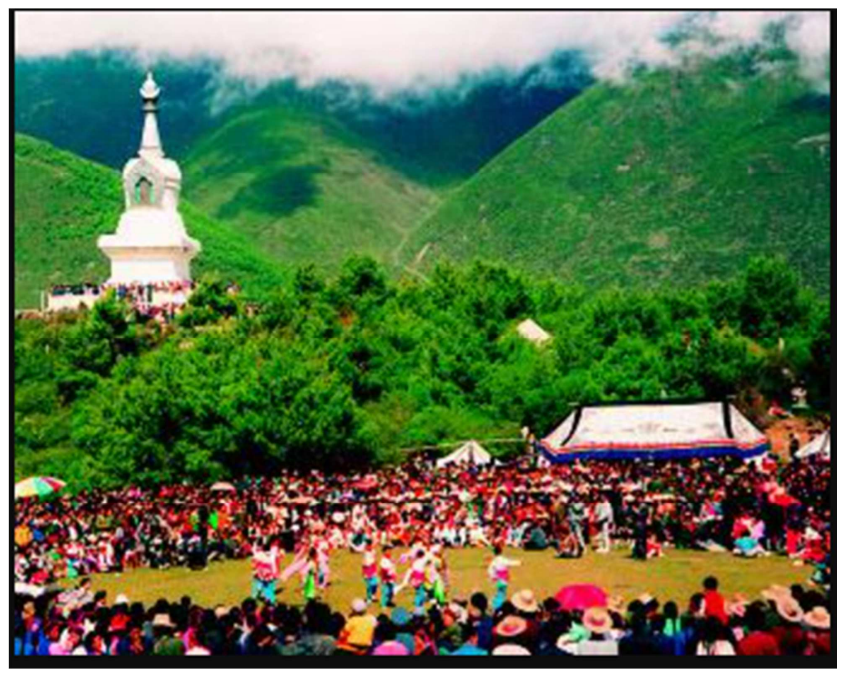

Figure 2. Zhuanshan day for Ganzi Tibet people.

The Ganzi Tibetan area has many holy mountains. Ganzi Tibetan people think that climbing holy mountains at will is forbidden. Hunting, digging, cutting, and throwing garbage on the mountain are not allowed. At the same time, the Ganzi Tibetan area also attaches great importance to forest protection. For example, the tribal law of Litang Tibetan area stipulates that "people are prohibited from entering the forest to dig medicine, no matter how much, whether they got or not, and whether they dig in their own land or others, they will be fined." The money charged for digging is 30 yuan (60 yuan for 2 people, and so on). Figure 2 shows the Zhuanshan day in Ganzi Tibet people. In Mula area, no holy trees are allowed to be cut, and no cutting is allowed in the area of other leaders. "These practices not only effectively protect the local mountains and forests but also increase the diversity of animals and plants, which provides the material basis for the Tibetan people to continue to reproduce and live in the harsh natural environment [9].” The Ganzi Tibetan people also have many tribal customary laws, taboos, and customs, such as punishment for those who violate the rules of customary law of destroying animal and plant resources. Punishments include being interrogated under criminal law, being ridiculed by members of the tribe, and taking certain economic punishment. Killing one male deer has a fine of 100 yuan for Tibet Yang, 50 yuan for the mother deer, 10 yuan for Tibetan sheep or rock sheep, 30 yuan for Swertia or fox, and 20 yuan for otters.

In addition, the Ganzi Tibetan people have formed many taboos and living customs to protect animal resources due to their awe and respect for nature. Such customs include the prohibition of hunting tigers, bears, wild yaks, and other sacred animals and protecting wild and domestic animals. With the enforcement of these rules on local people, the contents of the customary law of environmental protection can be implemented [10].

\subsection{Environmental Protection of the Jing Minority}

The Jing minority is a typical cross-border ethnic group with a population of less than one hundred thousand. The history of Jing cannot be separated from the sea. The Jing people live on the sea for generations. When they chase fish in the North Bay, they come to Wutou Island, Dongxing City, Guangxi Zhuang Autonomous Region. They settle when they see no people around as they will have better fishing grounds. The Jing people in Wutou Village mainly believe in the gods of sea and mountain, which is related to their life and production [11].

Offshore production has many uncertainties and dangers in offshore production. Villagers believe that "Bailong," their sea protection king, can keep them safe. The living environment of the seaside can be easily affected by typhoons. The mountain forest on land can prevent wind and sand and protect their homes, and villagers also believe in the "king of mountains." They perform annual worship in traditional religious places called "huting." Therefore, Wutou Village has a unique geographical environment of mountains and seas, which breeds a unique marine civilization. Moreover, its mountain forests are beautiful. Hence, two basic lines of marine ecological maintenance and forest resource protection have been formed in the aspect of environmental protection.

The current environmental protection customary law of the Jing nationality in Wutou Village mainly reflects in the village regulations for the protection of ancient trees, the family's oral habit of protecting herons and birds, and the fishing break of the Ha Festival celebration.

\subsubsection{Village Regulations}

Village regulations and civil conventions are the main forms of customary law. In the late Qing dynasty, the ban on mountain and forest protection resources was widely distributed in the Jing nationality area. The main village regulations for protecting forest resources mainly stipulate the protection of mountain forest strips, the location of mountain sealing, the behavior of destruction, and the manner of punishment. At present, relevant regulations are still implemented. For example, they could stipulate that anyone who steals or cuts trees without authorization will be fined 10 yuan per 500 grams, branches and leaves are included. Tree cutters has to apologize in public; not only shall they bear the 
liability for property compensation but also the responsibility of mental damage.

\subsubsection{Learning from Words Within the Family}

Learning from words within the family can influence the village atmosphere through moral inspiration. For example, the protection of herons is implemented by the Chen family through words within their family. The family treats ill birds, breeds and releases birds, improves the habitat environment of herons, and educate children not to hurt birds. Such behaviors affect an increasing number of people from Fangchenggang and help protect herons in a large scale. Moreover, Fangchenggang City is named the "hometown of Chinese egrets" [12].

\subsubsection{Festival Celebration}

The Ha Festival is an important traditional festival of the Jing nationality. It has an unwritten but binding standard, that is, no household may sail to sea or fish during the Ha Festival [13]. Figure 3 shows how the Jing nationality celebrates the Ha Festival. Jing people regard this festival as an important occasion to worship the king of Zhenhai. They thank the king of Zhenhai for their blessings in various forms, and they sincerely invite the king to Harting for service. This behavior helps promote the protection of the sea.

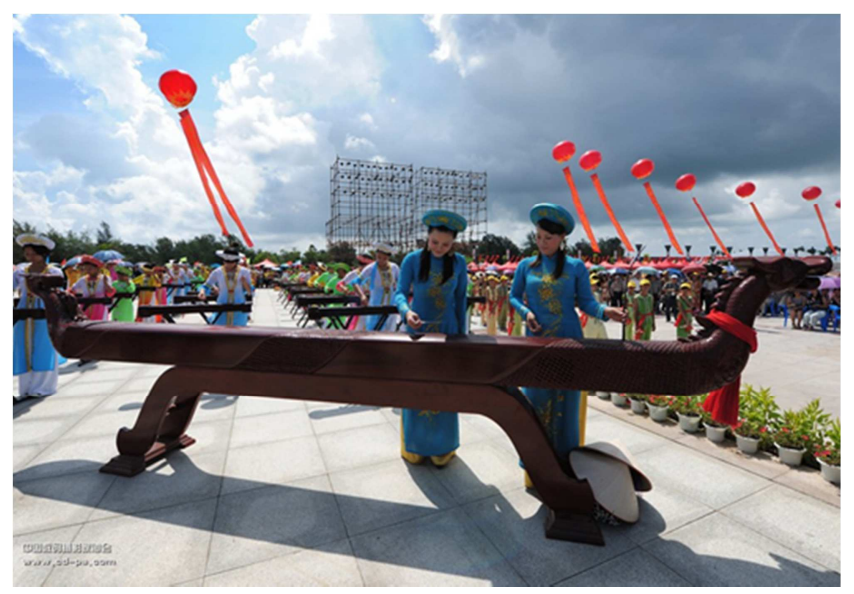

Figure 3. Celebration of Ha Festival by Jing nationality.

\section{Role of the Customary Laws of Ethnic Minorities}

\subsection{Ocial Function and Value}

The customary laws of ethnic minorities originate from the traditional culture of all ethnic groups and adhere to the concept of "all things have spirit." It is passed down from generation to generation through taboos, customs, myths, and stories, which has restricted people from damaging the natural environment and maintain the balance of ecological environment. This traditional culture promotes the harmonious relationship between the production of ethnic population and the environment and makes effective contribution to the ecological balance of ethnic areas. [14]

\subsection{Normative Function and Value}

When different ethnic minorities adapt to and transform their living environment, they explore and recognize the natural laws and form their own unique ecological environment consciousness. These production and living styles and primitive beliefs and customs gradually form the township regulations and customs in various ethnic areas. The environmental customary law is not only a legal norm but also a moral norm. Therefore, national environmental customary laws play a role in social norms for the survival and development of ethnic minorities; the regulation and control of the production and survival behavior of its members; and guidance, enforcement, evaluation, prediction and education in environmental ecological protection.

\subsection{Future of the Customary Laws of Environmental Protection}

The customary laws of environmental protection have strong effectiveness, which is reflected in the national environmental protection law. The concept of protecting the natural environment, developing moderately, and harmonizing human and nature is helpful for the recognition and implementation of national laws. Some of the contents of the customary laws of environmental protection of ethnic minorities can become an important source of local environmental protection legislation. [15] In addition, the customary laws of environmental protection have a certain promotion effect on the implementation of the national environmental protection legislation locally. At the same time, it can fill the vacancy of national ecological legislation. Given that the content of customary laws are not stipulated in the national law and do not violate the spirit, principle, and idea of national legislation, people should respect and apply it appropriately to make up for the gap of national environmental legislation and continue to play a positive role in environmental protection.

\section{Conclusion}

Customary laws are recognized by ethnic groups with the same geographical and cultural environment. It has played important role in environmental protection. The traditional culture inside customary law has been passed through old generations and adhere to the concept of "all things have spirit". The case study in Gelao nationality in Guizhou, Ganzi Tibetan, Jing minority demonstrated that the minorities showed their belief and worship for the natural resources and animal resources, they utilize different methods to show their respect for the holly mountain, forest, sea, animals and so on, the variety forms such as regulation, family words, as well as festival celebration had helped them to protect the environment. This should be utilized in the law legislation. And also the environmental customary law can not only fill the vacancy of the national environmental protection law but also could help the local people for implementation of the laws. The positive role the environmental customary played should 
be emphasized in the law legislation and implementation.

\section{Author Contributions}

Hongqing Ma contributed the whole draft of the paper. All authors have read and agreed to the published version of the manuscript.

\section{Funding}

This research received no external funding.

\section{References}

[1] QIAO Shiming. Research on the Construction of Ecological Legal System in Minority Areas [M]. Beijing: CHINA MINZU UNIVERSITY PRESS, 2009.

[2] GAO Qicai. Chinese Customary Law (Revised Edition) [M]. Beijing: China Legal Publishing House, 2008.

[3] GAO Qicai. Research on the Customary Law of Chinese Minority Nationalities [M]. Beijing: Tsinghua University Press, 2003.

[4] LIU Yigong, SHEN Wei. On the Environmental Protection Customary Law of China's Ethnic Minorities [J]. Science Economy Society: 2007, (04).

[5] YUAN Lihui. An Investigation on the Humanistic Value of the Gelao People's Worship of Ancient Trees [J]. REFORM \& OPENING, 2012 (8).

[6] ZHANG Xiaohui, et al. Gelao-Investigation in Hongfeng Village, Dafang County, Guizhou [M]. Kunming: Yunnan University Press, 2004.
[7] XIE Ailin. A Centennial Record of Gelao People [M]. Beijing: Chinese Literature and History Publishing House, 2008.

[8] Tashi Caicuo. A Preliminary Analysis of Tibetan Ecological Customary Law [D]. Beijing: Minzu University of China, 2012.

[9] MA Xiaoqin, YANG Deliang. Local Knowledge and Regional Ecological Environment Protection-Taking the Customary Law of Qinghai Tibetan Area as a Case [J]. Qinghai Social Sciences, $2006(2)$.

[10] LI lei. Tibetan Customary Law of Environmental Protection in Tibet [D]. Lhasa: Tibet University, 2016.

[11] WANG Xiao-long. Customary Laws from Ethnic Religious Activities and the Roles in Harmonious Society Construction: Taking the Customary Laws from the Ha Festival of the Jing as a Case [J]. Journal of Original Ecological National Culture, 2011: 3 (3).

[12] An elderly Jing nationality in Dongxing, Guangxi guarding the egret for 55 years [EB/ OL]. (2015-10-10) [2018-01-26]. http://www.chinadaily.com.cn/micro-reading/dzh/2015-10-10/ content 1424431.html.

[13] LIU Yanling. The Practical Value of Ecological Rule of Law of the Environmental Customary Law for Southwest Minorities [J]. Heilongjiang National Series, 2016 (4).

[14] Li Huang, Lijuan Tian, Lihua Zhou et al., Local cultural beliefs and practices promote conservation of large old trees in an ethnic minority region in southwestern China, Urban Forestry \& Urban Greening. 2020, 49126584.

[15] Anthwal, A., Gupta, N., Sharma, A., Anthwal, S., Kim, K. H., 2010. Conserving biodiversity through traditional beliefs in sacred groves in Uttarakhand Himalaya, India. Resour. Conserv. Recycl. 54 (11), 962-971. 